cambridge.org/cty

\section{Obituary}

Cite this article: Rudolph AM and Silverman NH (2020) Julien Ivor Ellis Hoffman. Cardiology in the Young 30: 1378-1379. doi: $10.1017 /$ S1047951120002802

\section{Author for correspondence:}

N. H. Silverman, E-mail: nsilver@stanford.edu

\title{
Julien Ivor Ellis Hoffman
}

\section{Abraham M. Rudolph and Norman H. Silverman}

University of California, San Francisco, CA 94143, USA

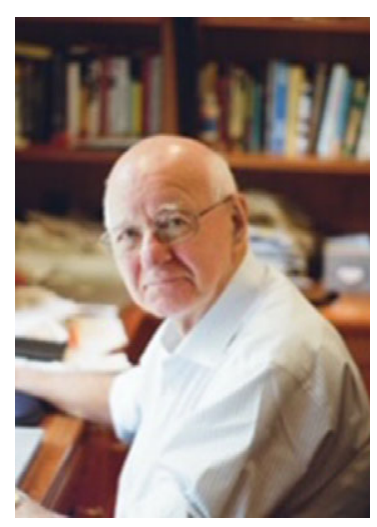

Sadly, Julien Hoffman died on 23 June, 2020. He was born in Salisbury (now Harare), Southern Rhodesia (now Zimbabwe) in 1925. He received the degree of BSc(Hon) in 1945 and graduated cum laude from the Medical School of the University of the Witwatersrand in Johannesburg, South Africa, in 1949 and began an internship in Internal Medicine at the Johannesburg General Hospital. In 1952, he was an intern and then a Registrar in Internal Medicine at Central Middlesex Hospital in London. He returned to Johannesburg in 1955 to a position of Registrar in Internal Medicine at the General Hospital. His career in Cardiology was initiated as a Research Fellow at the Royal Postgraduate Medical School in London in 1957. He then moved to the USA in 1959 as a Fellow in Paediatric Cardiology at the Children's Hospital, Boston, and in 1960 was a Fellow in the Cardiovascular Research Institute at the University of California, San Francisco. He returned to Rhodesia to practice clinical cardiology, but returned to the USA in 1962 to join Abraham Rudolph in the Paediatric Cardiology Division of the Department of Paediatrics at Albert Einstein College of Medicine in New York. In 1966, Rudolph and Hoffman joined the Paediatric Department at the University of California in San Francisco (UCSF) and also were appointed as Senior Staff of the Cardiovascular Research Institute. Although their clinical interests in Paediatric Cardiology were similar, Rudolph's research interests centred on fetal and neonatal cardiovascular function, whereas Hoffman was primarily interested in physiology of the coronary circulation; separate research laboratories were established. After 32 years, he became an Emeritus Professor in 1994, but continued to actively participate in clinical care and particularly, teaching. He also continued to consult with and advise former Fellows and to contribute to the literature.

During his achievement of his BSc Degree in Anatomy in 1945, Hoffman developed his first interests in research, directed to studies of spermatogenesis. He also began to appreciate the importance of statistics. While in Johannesburg, he assisted members of the faculty in Medicine in statistical analysis and expanded his expertise by association with John Kerrich, Chief of the Statistics Department at the University of the Witwatersrand. In 1964, he introduced a course in statistics for Fellows in the Cardiovascular Research Institute and taught this course for about 30 years. He was a member of the Biostatistics Group of UCSF, responsible for coordinating statistics practice and also served as a consultant in statistics for several medical journals.

In 2015, he published the book "Biostatistics for Medical and Biomedical Practitioners", which reviews the basic aspects, the applications and the reliability of statistics.

Early in his career in Paediatric Cardiology, Hoffman reported on the high incidence of spontaneous closure of ventricular septal defects, particularly in young children. This stimulated a continuing interest in the natural history of all congenital cardiovascular malformations. During the 50 years of practice in clinical paediatric cardiology, he has pursued this interest in natural history and has also assessed the effectiveness of various surgical procedures. He authored a book - The Natural and Unnatural History of Congenital Heart Disease, published in 2009. This presents an outstanding review of the natural history of the various congenital cardiovascular anomalies and how they respond to surgical procedures. He also discusses how variations in morphology and haemodynamics of the various lesions influence outcomes. 
Hoffman's main research interest was in the pathophysiology of the coronary circulation. Inadequate subendocardial blood flow was considered to be an important factor in causing myocardial damage, with interference with cardiac function. Usually, the extramural coronary arteries appeared to be normal, but the assessment of the intramural flows in different portions of the myocardium had not been feasible. In studies in dogs, Hoffman showed that the injection of radioactive-labeled microspheres could be used to study the regional distribution of blood flow and to measure actual flows to various segments of the myocardium. Using these techniques, he outlined the basic mechanisms contributing to subendocardial ischaemia. His studies demonstrated that regional flow in the myocardium was regulated by intramyocardial pressure; so, during systole, subendocardial flow was greatly reduced, but there was little effect on subepicardial flow.

Julien Hoffman was a dedicated and enthusiastic teacher. He made himself readily available for comment and advice to students, residents, fellows and faculty to discuss clinical issues, research interests and to provide guidance regarding statistics. He also maintained contact with many of his former fellows, now faculty members in institutions in the USA and abroad, to share in their interests and provide advice and criticism. He had a congenial personality and was frequently invited as a visiting professor and as a speaker at clinical and research conferences, because his informal presentations and lectures were always stimulating.
He served on many National Institutes of Health and other boards and committees and received many awards, including Fellowship of the Royal College of Physicians (FRCP), many distinguished visiting professorships and invited lectureships. He was also awarded an Honorary Doctorate in Medicine from his Alma Mater, the University of the Witwatersrand.

He delivered the annual UCSF Faculty Research Lecture, one of the highest honors awarded to a University of California academician, and had an endowed chair, the Julien, i.e., Hoffman Chair in Cardiac Surgery at UCSF, named in his honor.

Despite his exceptionally busy academic life, Julien found time to read avidly and travel extensively, to develop a deep understanding of and knowledge in an amazingly diverse number of subjects, including the collection and study of minerals. Julien was the epitome of integrity, humility and erudition with a brilliantly critical mind and sometimes acerbic sense of humour. He also played a great game of tennis, no doubt applying a superb understanding of mathematics and statistics to his shot placement to offset his lack of speed.

Julien leaves behind his loving wife of 34 years, Dr. Kathy Lewis, and two adult children, Anna, a neonatal intensive care nurse in the unit her mother formerly headed, and Daniel, a third-year surgical resident at the University of California in San Francisco.

He will be sorely missed by all who knew him. 